\title{
Squamous Cell Carcinoma in Non-Functioning Kidney Associated with Staghorn Calculi: Uncommon Presentation of Common Malignancy
}

\author{
Shankar Bastakoti ${ }^{1}$, Nirmal Lamichhane ${ }^{2}$ \\ ${ }^{1}$ Department of Pathology, B. P. Koirala Memorial Cancer Hospital, Bharatpur, Nepal \\ ${ }^{2}$ Department of Surgical Oncology, B. P. Koirala Memorial Cancer Hospital, Bharatpur, Nepal
}

\begin{abstract}
Cancers of the kidney account for $2 \%$ of all the total human cancer. Squamous cell carcinoma (SCC) of renal pelvis is a rare neoplasm, accounting for only 0.5 to $0.8 \%$ of malignant renal tumors. In most cases, renal SCC is associated with chronic infections, chronic renal calculi, radiotherapy or any factor that can irritate the urothelium. We report a female patient aged 60 years diagnosed with Right Non-functioning Kidney with Nephrolithiasis with Suspicious Mass. Histopathological diagnosis with Squamous Cell Carcinoma in Stage III with Staghorn Calculi. In long standing urolithiasis, possibility of concomitant harboring of malignancy needs to be taken into consideration.
\end{abstract}

Key words: Kidney, Squamous Cell Carcinoma, Staghorn Calculi

\section{Introduction}

Cancers of the kidney account for $2 \%$ of all the total human cancer. ${ }^{1,2}$ Kidney cancer is the ninth most common cancer in men and 14th most common in women worldwide. ${ }^{3}$

Squamous cell carcinoma (SCC) of the renal pelvis is a rare neoplasm, accounting for only 0.5 to $0.8 \%$ of malignant renal tumors. ${ }^{4}$ Although the incidence of this tumor in the kidney, is rare, whenever a renal mass is accompanied by a longstanding renal stone, and this differential diagnosis should be considered. ${ }^{6}$

In most cases, renal SCC is associated with chronic infections, chronic renal calculi, radiotherapy, or any factor that can irritate the urothelium. ${ }^{7,8}$ Other potential causes have been described in the literature, including tuberculosis, immunosuppression with azathioprine, analgesic abuse with phenacetin, radiation therapy and chronic rejection in a transplant kidney., ${ }^{7,10}$

\section{Case Report}

We report a case of a 60 years old female patient in 2019 $\mathrm{AD}$, she complained of chronic dull aching abdominal pain which was diagnosed as Right Non-functioning Kidney with Nephrolithiasis with suspicious mass after clinico-radiological evaluation. Right Nephrouretectomy was done, which on gross examination revealed kidney measuring $15 \times 10 \times 10 \mathrm{~cm}$ (Figure 1) with attached ureter measuring $7 \mathrm{~cm}$. On bivalving, a staghorn stone was noted(Figure 2) obstructing along with dilation and thinning of the renal parenchyma. An ill circumscribed mass measuring $7 \mathrm{~cm}$ involving the perinephric fat was noted.

On histopathology examination, (Figure $3 \& 4$ ) atypical squamous cells in sheets, lobules, and nests were noted. Cells are pleomorphic, round to oval vesicular chromatin, distinct nucleoli, and moderate cytoplasm. Individual cell keratinization and keratin pearls were noted. Also, necrosis and few mitotic figures were noted.

Correspondence

Dr. Shankar Bastakoti, Department of Pathology, B. P. Koirala Memorial Cancer Hospital, Bharatpur, Nepal, email:drshankarbastakoti@gmail.com 
Squamous Cell Carcinoma, Well Differentiated type was seen along with renal pelvis dysplasia and tumor extending through the perinephric fat. Hydronephrotic changes were noted. Ureter and vessel margins were unremarkable. Lymphovascular and perineural invasion was not visualized. The tumor was staged- AJCC Stage III (pTNM: pT3aNoMo). The patient had an uneventful postoperative course.

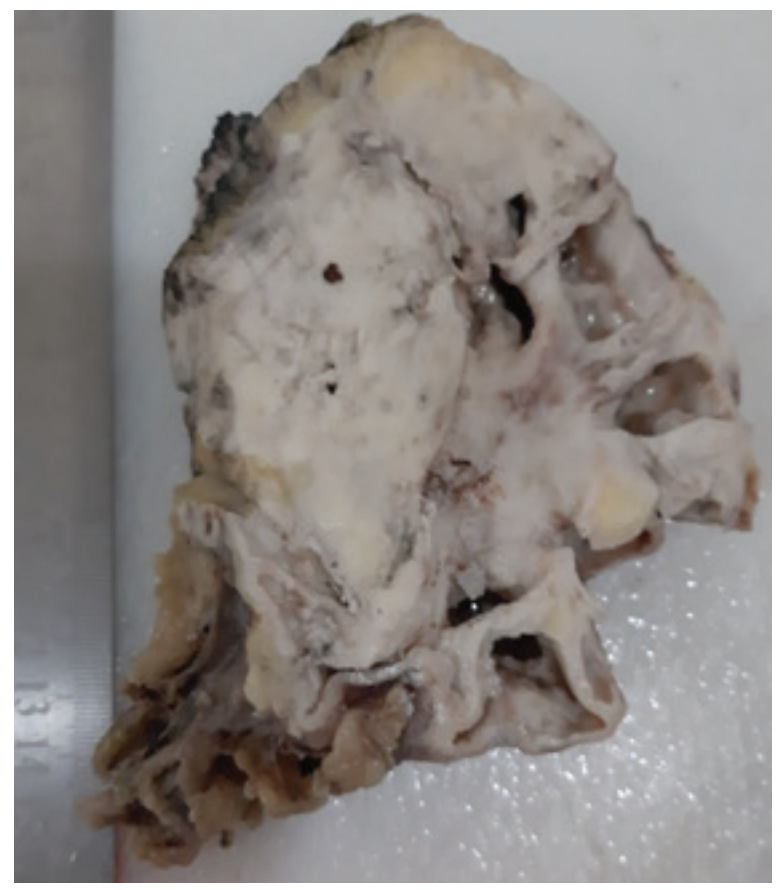

Figure 1 : Gross Specimen of Kidney Exhibiting Pelvicalyceal dilatation and infiltrating solid mass.

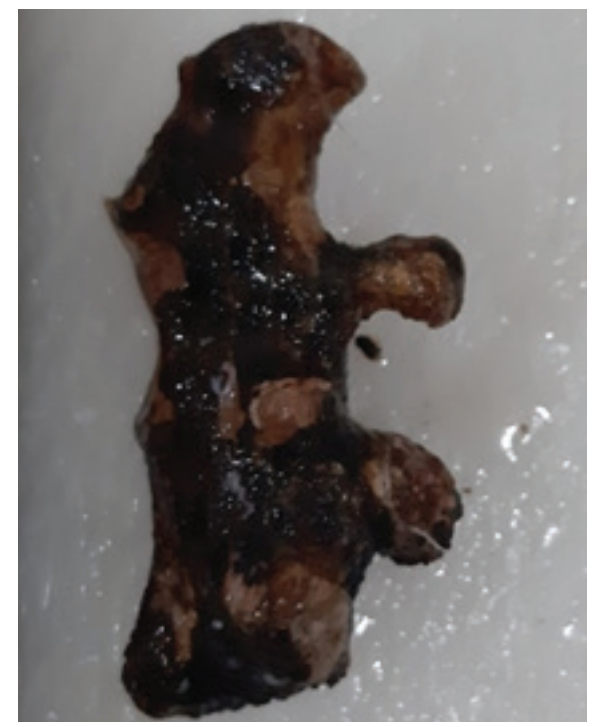

Figure 2: Staghorn Calculi was noted in the renal pelvis.

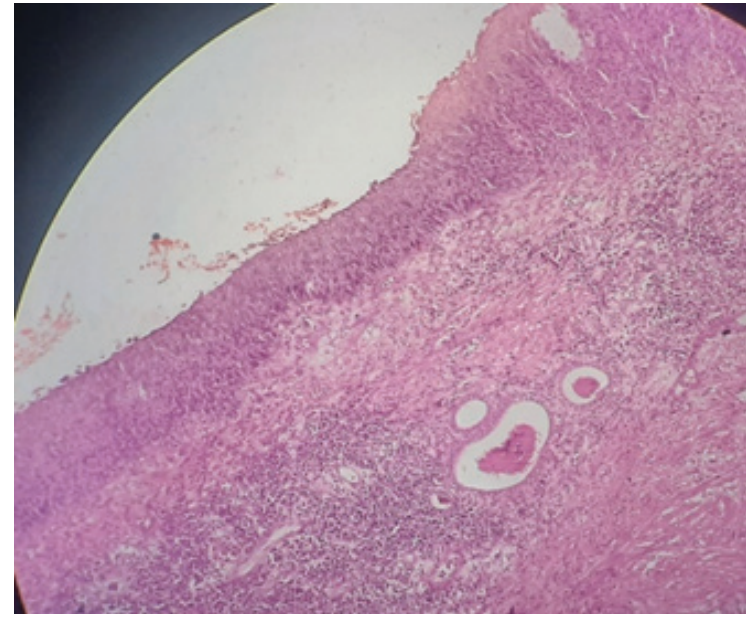

Microphotograph 3 - Renal Pelvis lining with severe dysplasia with underneath lymphocytic infiltration and few tubules (20x, H \& E)

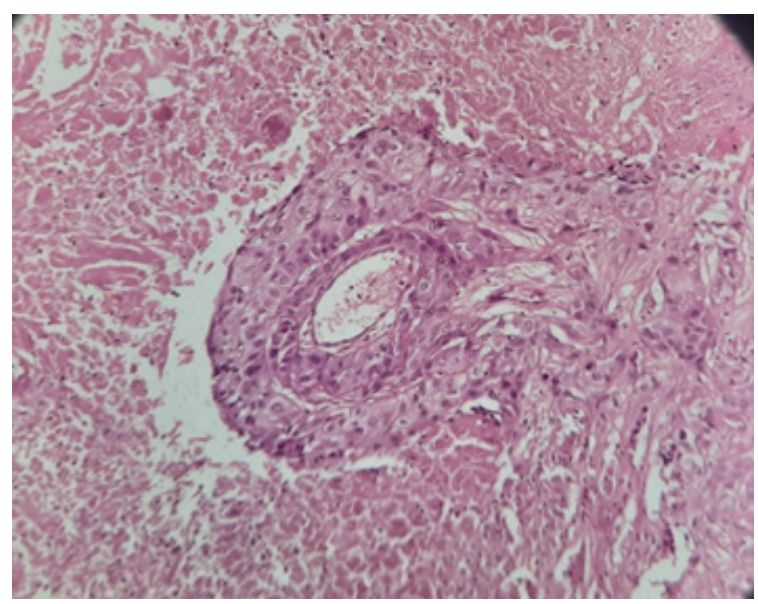

Microphotograph 4 - Tumor Proper showing tumor cells with surrounding necrosis. (40x, H\&E)

\section{Discussion}

According to the Globocan 2018, renal malignancy is 12 th in incidence and $2.3 \%$ out of total new cases in 2018. ${ }^{11}$ Most of these cases are renal cell carcinoma viz: clear cell (70\%), papillary (10-18\%), chromophobe (5$7 \%)$, collecting duct (1-2\%), MiT family translocation RCC (1.6-4\%), Clear cell papillary (1-4\%). ${ }^{3}$

Squamous cell carcinoma of Kidney is rare which usually present in an advanced stage. Squamous cell carcinomas of the renal pelvis are believed to develop following chronic irritation superimposed with infection leading to metaplasia then dysplasia and consequent development 
of invasive carcinoma. ${ }^{12}$

As in this case, SCC is frequently associated with calculus disease and hydronephrosis., ${ }^{42}$ In most of the cases the age of the patient was beyond 50 years. ${ }^{4,5,6,7,8,12}$

Insidious onset of the disease and lack of any pathognomonic sign or symptom confounds the delay in diagnosis. Due to this delay in diagnosis, tumor progress in the advanced stage, as in our case, Staghorn calculi was noted and tumor extended to perinephric fat.

Paraneoplastic syndromes have also been reported in association with SCC of the upper urinary tract. These patients are often found to have hypercalcemia, however, these features were not noticed in our patient. ${ }^{7}$

Even in the case of metastatic disease, nephrectomy should be performed to establish the histological diagnosis besides, local control of symptoms such as pain, hematuria, and elimination of the source of infection particularly if associated with renal calculi. ${ }^{12}$

Nephrectomy with or without ureterectomy is the recommended treatment in primary renal squamous cell carcinomas even in the presence of distant metastasis, to establish the diagnosis and symptomatic relief. Cisplatinum based chemotherapy and palliative radiotherapy as adjuvants are the post-surgery treatment but have shown minimal benefit. ${ }^{2,10}$

It is reported that the probability of 5-year survival is under $10 \%$, and the average postoperative survival rate is up to 7 months. ${ }^{8,10}$ In our case the current status of the patient is unknown as she was lost to follow-up.

\section{Conclusion}

In long-standing urolithiasis, the possibility of concomitant harboring of malignancy needs to be taken into consideration. Renal squamous cell carcinoma remains an unusual, unsuspected diagnosis of renal neoplasm with a dismal prognosis.

\section{References}

1. Lipworth L, Tarone RE, McLaughlin JK. The epidemiology of renal cell carcinoma. J Urol. 2006; 176(6 Pt 1):2353-2358. doi:10.1016/j. juro.2006.07.130.

2. Singh J, Hafiz A, Shafi A, Rather AR, Rasool M, Bashir S. Primary squamous cell carcinoma of the renal pelvis associated with staghorn calculi. JK Science. 2012;14:152-54.

3. Moch H, Cubilla AL, Humphrey PA, Reuter VE, Ulbright TM. The 2016 WHO Classification of Tumours of the Urinary System and Male Genital Organs; Renal Cell Tumor. 14-76.

4. Li MK, Cheung WL. Squamous cell carcinoma of the renal pelvis. J Urol. 1987; 138(2):269-71.

5. Zhang, X., Zhang, Y., Ge, C. et al. Squamous cell carcinoma of the renal parenchyma presenting as hydronephrosis: a case report and review of the recent literature. BMC Urol 20, 107 (2020). https:// doi.org/10.1186/s12894-020-00676-5.

6. Hosseinzadeh M, Mohammadzadeh S. Primary Pure Squamous Cell Carcinoma of Kidney Associated with Multiple Stag Horn Stones. Int Med Case Rep J. 2020;13:261-263 https://doi.org/10.2147/IMCRJ. S261022.

7. Paonessa, J., Beck, H. \& Cook, S. Squamous cell carcinoma of the renal pelvis associated with kidney stones: a case report. Med Oncol 28, 392-394 (2011). https://doi.org/10.1007/s12032-010-9704-z.

8. Salehipour M, Dastgheib N, Hosseinzadeh M, Makarem A, Rezvani A, Sanati A, Tayebi S. Primary renal pelvis and ureter squamous cell carcinoma (SCC): a rare case report and review of literature. Int Med Case Rep J. 2019 Jun 28; 12:189-192. doi: 10.2147/IMCRJ.S203283. PMID: 31303798; PMCID: PMC6605763.

9. Bhandari A, Alassi O, Rogers C, MacLennan GT. Squamous cell carcinoma of the renal pelvis. J Urol. 2010; 183:2023-4.

10. Holmang S, Lele SM, Johansson SL. Squamous cell carcinoma of the renal pelvis and ureter: incidence, symptoms, treatment and outcome. J Urol. 2007; 178:51-6.

11. GLOBOCAN. The global cancer observatory:Nepal factsheet. In: International Agency for Research on Cancer, World Health Organisation.2018. Available:http://gco.iarc.fr/today/data/factsheets/ populations/524-nepal-fact-sheets.pdf

12. Singh V, Sinha RJ, Sankhwar SN, Mehrotra B, Ahmed N. Squamous cell carcinoma of the kidney-rarity redefined: case series with review of literature. J Cancer Sci Ther. 2010; 2:082-085. doi:10.4172/19485956.1000028. 